\title{
Biocontrol of toxigenic strain of Aspergillus flavus isolated from the root tubers of safed musli (Chlorophytum borivilianum Sant. F) using its rhizospheric mycoflora
}

\author{
Yashasvita Chauhan \\ Mycology Research Lab, Department of Botany, Agra College, Agra (U.P.), INDIA \\ *Corresponding author. E-mail:yashasvita.tulip@gmail.com
}

Received: October 18, 2016; Revised received: March 2, 2017; Accepted: May 9, 2017

\begin{abstract}
Miraculous herb safed musli (Chlorophytum borivilianum Sant. F), family liliaceae, is well recognized for its immense potential as an aphrodisiac. The root tubers of this herbal drug were found to be invested with Aspergillus flavus during field and storage. Therefore, the present study was designed to explore the ability of 26 coexisting rhizospheric mycoflora to inhibit $A$. flavus invasion and subsequent aflatoxin contamination of safed musli. The interaction of these moulds with highly toxigenic strain (CB55) of $A$. flavus was evaluated by dual culture method and type of interaction was graded. Most likely antagonistic effects were shown by fifteen (15) moulds, out of which Type 'C' interaction was evidenced in the case of six moulds ; A. clavatus, A. terreus, Botryotrichum piluliferum, Candida albicans, Cephalosporium acremonium, and Cunninghamella sp. Further, ' $D$ ' type interaction was displayed by seven moulds which include A. niger, Colletotrichum sp., Drechslera sp., Mucor haemalis, Mycelia sterilia, Rhizopus arrhizus and Stachybotrys atra and 'E' type interaction was noted in the case of Trichoderma viride and Trihcothecium roseum. Regarding human health it is critical to use an ecofriendly approach to control the invasion of toxigenic moulds with root tubers of safed musli.
\end{abstract}

Keywords: Aflatoxin, Aspergillus flavus, Safed musli, Rhizosphere mycoflora

\section{INTRODUCTION}

Ancient system of Indian traditional medicine has described the white gold, safed musli (Chlorophytum borivilianum Sant. F) as an aphrodisiac. An antiaging, health restorative safed musli, now-a-days, widely used as an alternative to 'viagra'. The extract of root tubers of safed musli improves the quantity and quality of semen (Rath and Panja, 2013). But the root tubers of this herbal drug were found to be infested with Aspergillus flavus during field and storage (Chauhan et al., 2011). And the consequent mycotoxin elaboration contributes in reducing its productivity as well as posing serious health concerns to humans and animals (Yaling et al., 2008 and Averkieva, 2009). Aflatoxins produced predominantly by $A$. flavus and A. parasiticus are potent toxic, carcinogenic, mutagenic, immunosuppressive and teratogenic agents (Calvo et al., 2002; Jiang et al., 2005; Turner et al., 2005; Krishnamurthy et al., 2008 and Razzaghi- Abyaneh et al., 2013). They can directly influence the structure of DNA and the results into various genetic defects which can even lead to fetal mis-development and miscarriages.

Its low productivity and increased demand has raised the concern over the conservation of this endangered plant. Therefore, to meet its commercial demand, alternative strategies for the quality and quantity yield management of root tubers of safed musli are urgently required. Although, the use of chemicals has shown promising results, their continuous use disturbs the soil health which leads to poor crop and lower yields (Pandey and Saikia,2014). So, rhizosphereflora serves as a better option for effective biological control potentials. Therefore, the present investigation was undertaken to study the interaction between rhizosphere mycoflora and toxigenic strain of A. flavus (CB55) isolated from the root tubers of $C$. borivilianum.

\section{MATERIALS AND METHODS}

Sample collection: Each sample weighing 20-25 grams root tubers of safed musli (C. borivilianum), collected from wholesale dealers and farmers of eighteen different localities of Uttar Pradesh were kept in sterilized plastic bags.

The bags were sealed over the flame immediately to avoid any external contamination and then, stored in the refrigerator at the $4{ }^{0} \mathrm{C}$ temperature for further investigations.

Isolation of aflatoxigenic fungi associated with the samples of root tubers: The root tubers were screened for the association of moulds by surface washing, serial dilution method and agar plate technique using PDA and CDA media, suggested by Waksman (1927) and Graves and Hesseltine (1966). For the purpose, $25 \mathrm{gm}$ of sample was transferred to $250 \mathrm{ml}$ Erlenmeyer flask 
containing $50 \mathrm{ml}$ sterilized distilled water and shaken well for 15 to 30 minutes on a mechanical shaker. After shaking, the suspension was transferred into centrifuge tubes and centrifuged at $3000 \mathrm{rpm}$ for 5 minutes. The supernatant was discarded and the residue (pellet) was dissolved in $1 \mathrm{ml}$ of sterilized distilled water. After gentle shaking, $0.1 \mathrm{ml}$ of this suspension was poured into sterilized petriplate by sterilized pipette and then $20 \mathrm{ml}$ of lukewarm Czapek's dox agar medium was poured and dishes were gently shaken to disperse the medium and the spore suspension uniformly. In this way, ten replicates were prepared for each sample. After solidification of medium, the dishes were incubated at $28 \pm 10{ }^{\circ} \mathrm{C}$ for 5-7 days. Various aflatoxigenic strains including highly toxigenic strain (CB55) of A. flavus (Chauhan et al., 2011) so obtained were then sub-cultured, purified and maintained on CDA slants.

Determination of rhizosphere and rhizoplane flora of Chlorophytum borivilianum: Isolation and purification of rhizoshere and rhizosplane mycoflora was done by Warcup's method (Warcup, 1950). Soil sample was collected from root's vicinity, weighing 10 gm was transferred to $250 \mathrm{ml}$ Erlenmeyer flask containing 50 $\mathrm{ml}$ sterilized distilled water and shaken well in a mechanical shaker. After shaking, serial dilutions were prepared from the original mixture to obtain the dilution of $1: 10,1: 100$ and $1: 1000$. Then, the sterilized Petridishes were used and $1 \mathrm{ml}$ from each of the above -prepared dilution along with $20 \mathrm{ml}$ of lukewarm Czapek's dox agar medium was poured into them. Dishes were gently shaken to disperse the medium and spore suspension uniformly. Three replicates were prepared for each dilution, and such plates were incubated at $28 \pm 10^{\circ} \mathrm{C}$ for 5-7 days.

Similarly, rhizoplane flora was also determined. For this purpose, freshly collected and cleaned roots of safed musli were suspended in $50 \mathrm{ml}$ sterilized distilled water contained in a beaker and subjected to gentle shaking. After 15 minutes of shaking, the roots were taken out, and the suspension was centrifuged at 3000 rpm for 5 minutes. The supernatant was discarded and the residue was dissolved in $5 \mathrm{ml}$ sterile distilled water. Finally, $1 \mathrm{ml}$ of this suspension was poured into sterilized Petriplates to which $20 \mathrm{ml}$ sterilized PDA or CDA medium was added and shaken gently to disperse the spores in the medium. In this way, five replicates were made for each set. The plates were then incubated at $28 \pm 1{ }^{\circ} \mathrm{C}$ for 7 days. After the incubation period, the plates were studied for the occurrence of molds and then colonies of different fungi were identified tentatively, noted and counted. Different fungal species so obtained were then sub-cultured, purified and maintained on CDA medium.

Study of antagonistic behavior: Antagonistic interaction behavior of co-existing fungi was evaluated by dual culture technique on PDA medium against highly toxigenic strain (CB55) which was isolated from the root tubers of safed musli of $A$. flavus. Each pair was inoculated over the agar surface maintaining equidistance to all test pairs. The plates were incubated at 27 $\pm 2{ }^{\circ} \mathrm{C}$ and examined for 5-8 days and the type of interaction was graded according to Johnson and Curl (1972) as follows:

Mutual intermingling of the two organisms =A

Mutual inhibition on contact. The space between the

Table 1. Grading of fungi under Johnson and Curl (1972) type interaction.

\begin{tabular}{ll}
\hline $\begin{array}{l}\text { Interaction type with } \\
\text { toxigenic strain (CB55) } \\
\text { of } \text { Aspergillus flavus }\end{array}$ & Name of fungi \\
\hline A & $\begin{array}{l}\text { Alternaria alternata, Bipolaris rostrata, Helminthosporium sativum } \\
\text { Alternaria triticina, Aspergillus nidulans, Cladosporium Cladosporoides, Fusarium oxysporum, }\end{array}$ \\
B & $\begin{array}{l}\text { F. roseum, Penicillium citrinum, Rhizoctonia solani, Verticillium albo-atrum } \\
\text { Aspergillus clavatus, Aspergillus terreus, Botryotrichum piluliferum, Candida albicans, Cepha- } \\
\text { losporium acremonium, Cunninghamella sp. }\end{array}$ \\
D & $\begin{array}{l}\text { Aspergillus niger, Colletotrichum sp. Drechslera sp. Mucor haemalis, Mycelia sterilia, Rhizopus } \\
\text { arrhizus, Stachybotrys atra }\end{array}$ \\
E & Trichoderma viride, Trichothecium roseum \\
\hline
\end{tabular}

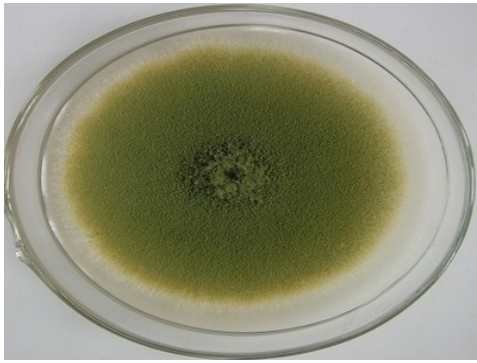

Fig. 1. Showing the uniform circular colony of Aspergillus flavus(CB55).

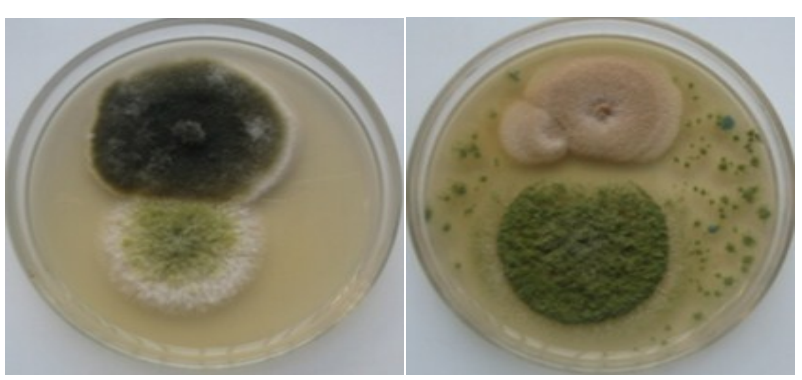

Fig. 2. Type A interaction. Fig. 3.Type $C$ interaction. 


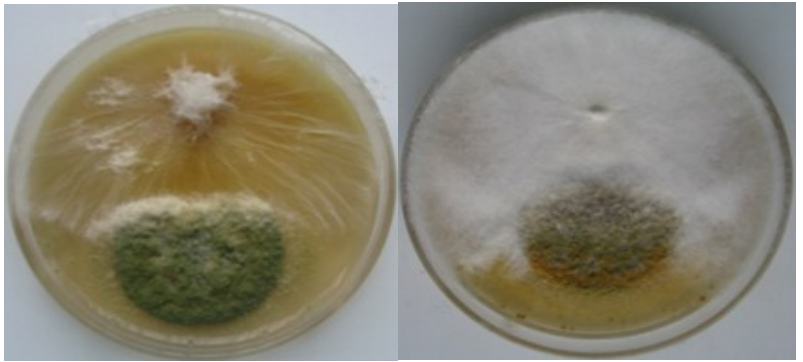

Fig. 4. Type D interaction.

Fig. 5. Type D interaction.

colonies is small but clearly marked $=\mathrm{B}$

Mutual inhibition at a distance $=\mathrm{C}$

Inhibition of one organism on contact, the antagonist continues to grow unchanged or at a reduced rate through the colony of the inhibited organism $=\mathrm{D}$

Inhibition of one organism at a distance, the antagonist continues to grow through the resulting clear zone, at an unchanged or reduced rate $=\mathrm{E}$

\section{RESULTS AND DISCUSSION}

The present results revealed that the co-existing rhizosphere mycoflora of root tubers of safed musli screened showed different interaction types with toxigenic isolate of $A$. flavus (CB55) [Figs. 2-7 and Table 1]. In general, three co-existing moulds showed ' $A$ ' type of interaction (Fig. 2). These include Alternaria alternata, Bipolaris rostrata, and Helminthosporium sativum. Eight co-existing rhizosphere moulds showed 'B' type of interaction (Fig.7). These included Alternaria triticina, Aspergillus nidulans, Cladosporium cladosporoides, Fusarium oxysporum, Fusarium roseum, Penicillium citrinum, Rhizoctonia solani and Verticillium albo-atrum. These fungi were treated as slightly antagonistic to toxigenic Aspergillus flavus. Interestingly, ' $\mathrm{C}$ ' type of interaction (Fig. 3) was evidenced in the case of Aspergillus clavatus, Aspergillus terreus, Botryotrichum piluliferum, Candida albicans, Cephalosporium acremonium, and Cunninghamella sp. Further, 'D' type interaction (Figs. 4 and $5)$ was displayed by seven moulds which include $A s$ pergillus niger, Colletotrichum sp., Drechslera sp., Mucor haemalis, Mycelia sterilia, Rhizopus arrhizus and Stachybotrys atra while 'E' type (Fig. 6) interaction was noted in the case of Trichoderma viride and Trihcothecium roseum. Type ' $\mathrm{C}$ ' moulds were regarded as antagonistic to $A$. flavus while type ' $D$ ' and type 'E' were adjudged as highly antagonistic to Aspergillus flavus. Hence, they can be used to prevent the growth of A. flavus and consequently, the elaboration of the aflatoxins.

Thus, the interaction of $A$. flavus with different rhizospheric mycoflora of root tubers of safed musli supports their possible bio-control role against the toxigenic strains of $A$. flavus.

The first fundamental idea towards the development of prevention strategies and reduction of human exposure

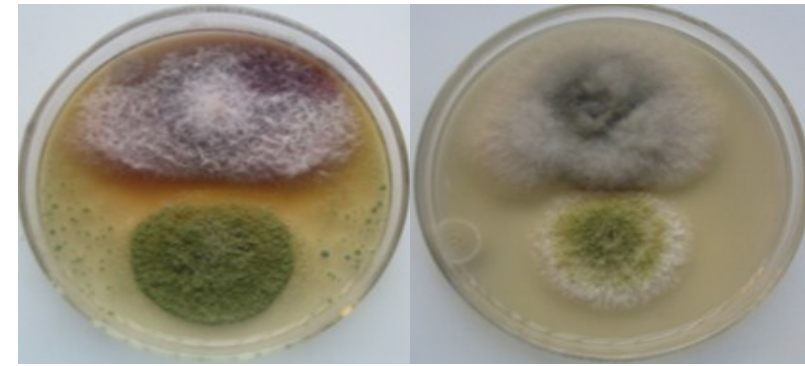

Fig. 6. Type E interaction. Fig. 7. Type B interaction.

Figs. 2-7. Showing interactions of various antagonistic fungi with highly toxigenic strain (strain CB55) of A. flavus.

to hepato-carcinogenic aflatoxins is, to understand the interaction between the fungus and the host plant. Aspergillus sp. infect crop during cultivation, but aflatoxins continue to accumulate in post-harvest period under poor storage conditions, which favor fungal growth and toxin production. Therefore, according to Wild and Hall (2000) and Groopman and Kensler (2005), post-harvest interventions contribute significantly in controlling aflatoxin.

In the past, many researchers have emerged highlighting the role of microorganisms as bio-control agents. The antifungal abilities of some beneficial microbes have been known since the 1930's, and there have been extensive efforts to use them for plant disease control since then (Ruiquian et al., 2004). Reddy and Reddy (1983) studied interaction of co-invading fungi with toxigenic strains of A. flavus. Cho et al. (2009) showed a new strain of Bacillus pumilus isolated from Korean soybean sauce which showed potent antifungal activity against the $A$. flavus and $A$. parasiticus. Recently, Kong, (2010) reported a strain of marine bacterium Bacillus megaterium which could be used as biocontrol agent against post-harvest fungal diseases caused by $A$. flavus and Guillermina et al. (2011) showed the effect of lactic acid bacteria on $\mathrm{AFB}_{1}$ production by Aspergillus species under in vitro conditions. Previously, some other studies have alsoreported a number of Bacillus, Pseudomonas, Ralstonia, Burkholderia and lactic acid bacteria (Streptococcus) strains which could inhibit growth of $A$. flavus and possibly aflatoxin production (Palumbo et al., 2006; Nesci et al., 2005; Bottone and Pelusco, 2003). In another report by Ciegler et al. (1966), Flavobacterium auranticum was found to remove aflatoxin from various foods irreversibly. Many reports on this organism appeared since then (Hao et al.,1967; Lillehoj et al., 1967 and Line et al., 1994).

Many studies have also accessed the efficacy of yeast as bio-control agent. Some saprophytic yeast species (such as Candida krusei and Pichia anomala) have been shown as promising biocontrol agents against $A$. flavus (Masoud and Kaltoft, 2006).

There are other fungi such as some species of Tricho- 
derma which was found interacting in the present study has already been recognized as the most potent biological control agent for certain plant diseases from the last 20 years (Inglis, 2002). Other similar studies indicating inhibition of aflatoxin production by $A$. flavus and $A$. parasiticus when cultured with Trichoderma sp. was shown by Gachomo and Kotchoni (2004). Even the non-toxigenic strains of Aspergillus flavus could be used to displace toxigenic strains and reduce aflatoxin contamination. Their bio-control potential has already been provedin various studies (Dorner, 2004; Cardwell and Henry, 2004; Abbas et al., 2006; Pitt and Hocking, 2006; Dorner, 2008; Yin et al., 2008; Tran-Dinh et al., 2013 and Pitt et al., 2015).

Similarly, Azziz et al. (1997) found Aspergillus niger and Trichoderma viride to be strongly antagonist, inhibiting the growth of $A$. flavus by $87 \%$ and $66 \%$, respectively whereas Aspergillus versicolor, Fusarium moniliforme, Paecilomyces variotii and Emericella quadrillineata inhibited the growth of $A$. flavus by less than $51 \%$. Cvetnic and Pepljnjak (2007) studied the interaction of 25 moulds strains of Alternaria sp., Cladosporium sp., A. flavus and A. niger used as biocompetitive agents. Their result confirmed antagonistic interaction between all the strains tested with Alternaria $\mathrm{sp}$. and Cladosporium $\mathrm{sp}$. and aflatoxin $\mathrm{B}_{1}$ production was decreased up to $100 \%$. In mixed cultures with Mucor sp., aflatoxin $\mathrm{B}_{1}$ inhibition ranged from 50 to $70 \%$. Martin et al. (2008) showed the antagonistic effects of A.niger (69.5\%), A. fumigatus (47.6\%) and $A$. terreus $(47.6 \%)$ and concluded that the development of Aspergilla strains concomitantly with competent aflatoxin producing moulds has a significant influence on the natural biosynthesis pattern. Above mentioned studies, clearly indicates the antagonistic role of various moulds against $A$. flavus.

In a very similar study by Roy et al. (2008), the antagonistic interaction between toxigenic strains of $A$. flavus and co-existing fungi of maize rhizosphere was observed. The author used the same Johnson \& curl's method for interaction categorization. The only difference between the study mentioned above and the present report is the usage of the experimental plant i.e. safed musli. Their findings are similar to the observations of the present investigation. Hence, all the previous studies give more validation to the results and scope of further significant findings on the natural way of treating the concerned problem.

\section{Conclusion}

The evaluation of the interaction of twenty six (26) co-invading rhizosphere moulds with highly toxigenic strain (CB55) of A.flavus showed different types of responses towards toxigenic isolate of A.flavus. The interaction type ' $\mathrm{A}$ ' was demonstrated by three moulds while another 8 moulds showed type ' $\mathrm{B}$ ' interaction. These fungi were treated as slightly antagonistic to toxigenic $A$. flavus. Six moulds displayed type ' $\mathrm{C}$ ' interaction. Type ' $\mathrm{D}$ ' interaction was evidenced in case of seven molds. Interestingly type ' $\mathrm{E}$ ' interaction was noted in the case of only two molds, i.e., Trichoderma viride and Trichothecium roseum. According to Johnson and Curl's interaction type and behavior of moulds, Type ' $\mathrm{C}$ ' moulds were considered as moderately antagonistic to $A$. flavus while type ' $\mathrm{D}$ ' and type ' $E$ ' were adjudged as highly antagonistic to A. flavus. Hence, they could be used to prevent A. flavus and consequently the aflatoxin contamination. Hence, present study revealed that safed musli (Chlorophytum borivilianum), sold commercially as an important herbal medicine which nourishes the tissues of the nervous and reproductive systems, is contaminated with mycotoxins particularly aflatoxin $\mathrm{B}_{1}$ at levels exceeding regulations of an international organization like FAO (1977). Thus, it is essential to take necessary steps to minimize mold infestation and mycotoxin contamination in crude herbal drugs such as root tubers of safed musli, which is a highly priced herbal drug owing to its use as a fertility and immunity booster.

\section{REFERENCES}

Abbas, H. K., Zablotowicz, R. M., Bruns, H. A. and Abel, C. A. (2006). Biocontrol of aflatoxin in corn by inoculation by non-aflatoxigenic Aspergillus flavus isolates. Biocontrol Sci. Technol., 16: $437-449$

Azzis, N. H., Shahin, A. A. M. (1997). Influence of other fungi on aflatoxin production by Aspergillus flavus in maize kernels. J. food safety, 1712:113-123

Averkieva, O. (2009). Mycotoxins in Grains harvested in 2008 P: wheat. Kemin Industries, Inc.(Contamina Windows Explorer).

Bottone, E. J. and Peluso, R. W. (2003). Production by Bacillus pumilus (MSH) of an antifungal compound that is active against mucoraceae and Aspergillus species. Preliminary report. J. Med. Microbiol., 52: 69 - 74

Calvo, A. M., Wilson, R. A., Bok, J. W. and Keller, N. P. (2002). Relationship between secondary metabolism and fungal development. Microbiology and Molecular Biology Reviews, 66: 447 - 459

Cardwell, K. F. and Henry S. H. (2004). Risk of exposure to and mitigation of effect of aflatoxin on human health: a West African example. J. Toxicol Toxin Rev., 23 (2\& 3): $217-247$

Chauhan, Y., Singh, R. K., Singh, R. and Singh, S. (2011). Toxigenic moulds associated with root tubers of safed musli. I.J.S.R., 2(3):69-72

Cho, K. M., Math, R. K., Hong, S. Y., Islam, S. M. A., Mandanna, D. K., Cho, J. J., Yun, M. G., Kim, J. M., Yun, H. D. (2009). Iturin produced by Bacillus pumilus HY1 from Korean soybean sauce (Kanjang) inhibits growth of aflatoxin producing fungi. Food Control, 20:402 406

Ciegler, A., Lillehoj, B., Peterson, R. E. and Hall, H. H. (1966). Microbial detoxification of aflatoxin. Appl. Microbiol., 36: $1-66$

Cvetnic, Z. and Pepljnjak, S. (2007). Interaction between certain moulds and Aflatoxin $\mathrm{B}_{1}$ producer Aspergillus 
flavus NRRL 3251

Dorner, J. W. (2004). Biological control of aflatoxin contamination of crops. Toxin Reviews, Philadelphia, 23 (2\&3): $425-450$

Dorner, J. W. (2008). Management and prevention of mycotoxin in peanuts. Food Additives And Contaminants, Ovon, 25(2): $203-208$

FAO (1977). Food and agriculture organization. UN Report AGS: M 1SC / 77 / 7, 26 Pp.

Gachomo, E. W. and Kotchoni, S. O. (2004). The use of Trichoderma harzianum and T. viride as potential Biocontrol Agents against Peanuts Microflora and their effectiveness in reducing aflatoxin contamination of infected Kernels. Res. Article.

Graves, M. and Hesseltine, C. W. (1966). Fungi in flour and refrigerated dough products. Mycopath et Mycol. Appl., 29: $277-290$

Groopman, J. D. and Kensler, T. W. (2005). Role of metabolism and viruses in aflatoxin induced liver cancer. Toxicol Appl. Pharmocol., 206: 131 - 137

Guillermina, M., Juri - F., Muzzolon, J. A., Dalcer, A. M. and Magnol, C. E. (2011). Effect of acid lactic bacteria isolated from faces of healthy dogs on growth parameters and aflatoxin $\mathrm{B}_{1}$ production by Aspergillus sp. in vitro. Mycotoxin Research, 27(4): 273 - 280

Hao, D. Y. and Brackett, R. E. (1967). Removal of aflatoxin $\mathrm{B}_{1}$ from peanut milk inoculated with Flavabacteriumauranticum. J. Food Sci., 53: 1384 - 1386

Inglis, G. D., Kawchuk, L. M. (2002). Comparative degradation of oomycete, ascomycete and basidiomycetes cell walls by mycoparasitic and biocontrol fungi. Can. J. Micribiol., 48(1): 60 - 70

Jiang, Y., Jolly, P. E., Ellis, W. O., Wang, J. S., Phillips, T. D. and Williams, J. H. (2005). Aflatoxins $B_{1}$ albuminadduct levels and cellular immune status in Ghanaians. Int. Immunol., 6: 807-814

Johnson, L. F. and Curl, E. A. (1972). Methods for research on the ecology of soil borne plant pathogens. Burgess Publishing Co., Minneapolis, Pp. 178

Kong, Q., Shan, S., Liu, Q., Wang, X. and Yu, F. (2010). Biocontrol of Aspergillus flavus on peanut kernels by use of a strain of marine Bacillus megaterium.Int. J. Food. Microbiol., $139(1-2): 31-35$

Krishnamurthy, Y. L., Shashikala, J., Naik, B. S. (2008). Antifungal potential of some natural products against Aspergillus flavus in soybean seeds during storage. Journal of Stored Products Research, 44: 305 - 309

Lillehoj, E. B. and Ciegler, A. (1967). Inhibition of DNA synthesis in Flavobacterium aurantiacum by aflatoxin $\mathrm{B}_{1}$. J. Bacteriol., 94: 787

Line, J. E. Brackett, R. E. and Wilkison, R. E. (1994). Evidence for degradation of aflatoxin $\mathrm{B}_{1}$ by Flavobacterium aurantiacum. J. Food. Proc., 57: $788-791$

Martins, H. M. Almeida, I., Marques, M. and Bernando, F. (2008). Interaction of wild strains of Aspergilla with Aspergillus parasiticus ATCC15517 and aflatoxin production. Int J Mol Sci., 9(3): 394-400

Masoud, W. and Kaltoft, C. H. (2006). The effects of yeast involved in the fermentation of Coffea Arabica in East Africa on growth and Ochratoxin A(OTA) production by Aspergillus ochraceus. Int. J. Food Microbiol., 06
(2):229-234

Nesci, A. V., Bluma, R. V. and Etcheverry, M. G. (2005). In vitro selection of maize rhizobacteria to study potential biological control of Aspergillus section Flavi and aflatoxin production. Eur. J. Plant Patho., 113(2):159-171

Palumbo, J. D., Baker, J. L. and Mahoney, N. E. (2006). Isolation of bacterial antagonists of Aspergillus flavus from almonds. Microb Ecol., 52 (1): 4552

Pandey, R. and Saikia, S. K. (2014). Rhizospheric Bioweapons for tuber yield enhancement in Chlorophytum borivilianum against Meloidogyneincognita infestation. J. Plant Biochem Physiol., 2:1

Pitt, J. I. and Hocking A. D. (2006). Mycotoxins in Australia: biocontrol of aflatoxin in peanuts. Mycopathologia, 162(3): $233-243$

Rath S. K. and Panja, A. K. (2013). Clinical evaluation of root tubers of shweta musali (Chlorophytum borivilianum L.) and its effect on semen and testosterone. Ayu., 34(3):23-275

Razzaghi-Abyaneh, M. (2013).Aflatoxin: Recent Advances and Future Prospects. Intech, Croatia.

Reddy, A. S. and Reddy, S. M. (1983). Interaction of different seed borne fungi of til (Sesamum indicum L.) and its effect on aflatoxin production by Aspergillus flavus. In, Proc. Symp. Mycotoxin in Food and Feed, K. S. Bilgrami, T. Prasad and K. K. Sinha (Eds.). Allied Press, India, Pp. $293-296$

Roy, A. K., Singh, A. N., Mandal, N. L. and Roy, S. (2008). Antagonistic interaction between toxigenic strains of Aspergillus flavus and co-existing fungi of maize rhizosphere. Indian Phytopath, 61 (3)

Ruiquian, L., Qian, Y., Jhanaboripat, D., Thansukon, P. (2004). Bicontrol of Aspergillus flavus and Aflatoxin production, KMITL Journal of Science and Technology, Vol. (4): ISSN: $1685-2045$

Tran-Dinh T., Pitt, J. I. and Marwell, P. J. (2013). Selection of non-toxigenic strains of Aspergillus flavus for biocontrol of aflatoxins in maize in Thailand. J. Biocontrol science and Technology, 24(6): 652-661

Turner, P., Sylla, A., Gong, Y., Diallo, M., Sutcliffe, A., Hall, A. and Wild, C. (2005). Reduction of exposure to carcinogenic aflatoxins by post harvest interventions measures in West Africa, A community based intervention study. Lancet., (365):1950-1959

Waksman, S. A. (1927). Principles of soil microbiology. Bailleire Tindall \& Co., London.

Warcup, J. H. (1950). Isolation of fungi from hyphae present in soil. Nature, 175: 953

Wild, C. P. and Hall, A. J. (2000). Primary prevention of hepatocellular carcinoma in developing countries. $\mathrm{Mu}$ tat Res., 462: 2-3

Yaling, W., Tongjie, C., Guozhong, L., Chunsan, Q., Huiyong, D., Meiling, Y., Bert-Andree, Z. and Gerd, S. (2008). Simultaneous detection of airborne aflatoxin and zearalenone in poultry house by immunoaffinity column and high performance liquid chromatography. Environ. Res., (107): 139-144

Yin, Y-ni, Yan, L-y; Jiang, J-h and Ma, Z-h (2008). Biological control of aflatoxin contamination of crops. $J$. Zhejiang Univ. Sci. B., 9(10): 787 - 792 